\title{
BENTUK VISUAL KOSTUM TARI MERAK JAWA BARAT KARYA IRAWATI DURBAN ARDJO
}

\author{
Venny Agustin Hidayat \\ Program Pascasarjana Institut Seni Indonesia Yogyakarta \\ E-mail: vennytintah@gmail.com
}

\begin{abstract}
RINGKASAN
Tari Merak Jawa Barat, merupakan jenis tarian tontonan (pertunjukan). Tari Merak pertama kali diciptakan oleh Rd. Tjetje Somantri pada tahun 1955. Kemudian pada tahun 1965, tari Merak dikemas kembali oleh Irawati Durban Ardjo, yang bertujuan untuk dipertunjukkan pada misi kesenian Soekarno. Tari Merak yang sering kita jumpai saat ini merupakan Tari Merak karya Irawati Durban Ardjo.Tarian ini mempresentasikan keindahan yang dimiliki oleh burung merak pada saat burung merak jantan melebarkan ekornya. Kebanyakan masyarakat Indonesia salah berasumsi jika tarian ini bercerita tentang kehidupan burung merak betina, sedangkan sang jantanlah yang memamerkan keindahan bulu ekornya. Sang jantan melakukan gerak-gerik yang tampak seperti tarian gemulai untuk menunjukkan pesona dirinya, sehingga sang betina terpesona dan bersedia kawin dengannya. Gerakan itulah yang mengekspresikan dibuatnya Tari Merak. Untuk mendukung keindahan tari, maka dibuat bentuk visual Merak pada kostum Tari Merak yang telah diinovasikan oleh Irawati. Irawati mengonsepnya melalui ide-ide kreatif dan mengindahkan esensi burung merak pada bentuk visual. Beberapa bagian kostum tari Merak Irawati, yaitu siger (mahkota), susumping, giwang (anting), kelat bahu, garuda mungkur, gelang tangan, kemben, ekor, Ikat pinggang, kacih, selendang, dan sinjang. Kostum yang memiliki banyak unsur estetika seperti garis (lurus, lengkung, bergelombang), bentuk (lingkaran, setengah lingkaran, persegi panjang, ekor merak, dan penyederhanaan burung merak), ornamen (ragam hias binatang, ragam hias tumbuhan, geometris, ulir). Beberapa motif yang digunakan yaitu motif ekor, bulu, ataupun keseluruhan bentuk burung merak.
\end{abstract}

Kata Kunci: Bentuk visual kostum, Irawati Durban Ardjo, Tari Merak Jawa Barat.

\begin{abstract}
Peacock Dance, is a type of spectacle dance (performance). The Peacock Dance was first created by Rd. Tjetje Somantri in 1955. Then in 1965, the Merak dance was repackaged by Irawati Durban Ardjo, which aimed to be performed on Soekarno's art mission. The Peacock Dance that we often encounter at the moment is the Peacock Dance by Irawati Durban Ardjo.

This dance presents the beauty of peacocks. The peacock is the inspiration for the creation of the Peacock dance and its beauty is found when the male peacock widens its tail. Most Indonesian people wrongly assume that this dance tells the story of the life of a female peacock, while the male exhibits the beauty of its tail feathers. The male performs movements that look like graceful dances to show his charms, so that the female is fascinated and willing to marry him. That movement expresses the Peacock Dance.
\end{abstract}


With the visual form of the Peacock Dance costume that has been innovated by Irawati. Irawati conceptualized it through creative ideas and heeded the essence of the peacock in visual form. Some parts of the Merraw Irawati dance costume, namely siger (crown), susumping, ear studs (earrings), kelat shoulders, garuda mungkur, wristbands, kemben, tail, belt, belts, shawls, and sinjang. Costumes that have many aesthetic elements such as lines (straight, curved, wavy), shapes (circles, semicircles, rectangles, peacock tails, and simplifications of peacocks), ornaments (various animal decoration, plant decoration, geometric, threaded). Some of the motifs used are the tail, feather, or overall shape motif.

Keywords: Costume visual form, Irawati Durban Ardjo, Peacock Dance in West Java.

\section{PENDAHULUAN}

Masyarakat Jawa Barat dikenal sebagai masyarakat agamis yang sarat dengan kekayaan warisan budaya serta nilai-nilai luhur tradisional. Salah satu contoh budaya yang banyak dikenal oleh masyarakat adalah Tari Merak.

Dengan berjalannya waktu, Tari Merak telah tampil di panggung dalam dan luar Negeri. Untuk mengharumkan nama Bandung dan Indonesia sejak 50 tahun yang lalu, suatu perjalanan yang panjang dalam menebar keindahannya. Tari kreasi baru yang diciptakan oleh Raden Tjetje Somantri pada tahun 1955, kemudian Irawati Durban Ardjo menggubah dan mengkreasikannya kembali pada tahun 1965. Tari Merak yang diciptakan oleh Tjetje dan Irawati mempunyai perbedaan yang sangat signifikan, baik dari kostum maupun gerak tari. Akan tetapi Irawati menciptakan Tari Merak, berpijak dari karya Tjeje Soemantri.
Burung Merak, sebagai salah satu jenis burung yang bulunya sangat indah merupakan inspirasi diciptakannya Tari Merak. Keindahannya sangat terlihat jelas pada saat burung merak jantan melebarkan bulu-bulu ekornya. Kebanyakan masyarakat Indonesia salah berasumsi jika tarian ini bercerita tentang kehidupan burung merak betina, sedangkan sang jantanlah yang memamerkan keindahan bulu ekornya. Sang jantan melakukan gerakgerik yang tampak seperti tarian gemulai untuk menunjukkan pesona dirinya, sehingga sang betina terpesona dan bersedia kawin dengannya. Gerakan-gerakan itulah yang menginspirasi diciptakannya Tari Merak.

Kehadiran tari pada kehidupan manusia dapat memilliki fungsi yang berbeda-beda tergantung dari kebutuhannya masing-masing. Dahulu, Tari Merak merupakan tari penyambutan untuk tamu kehormatan Negara atau tamu-tamu penting pada zamannya. 
Namun seiring berkembangnya zaman Tari Merak dapat ditampilkan pada berbagai macam acara, seperti upacara pernikahan, acara pentas seni, festival, penerimaan tamu agung, dan lain sebagainya.

Ciri khas pada pertunjukan Tari Merak, dapat dilihat dari pakaian yang dikenakan pada penari yang merepresentasikan burung Merak yang terlihat pada bulu dan ekor burung merak. Kain dan baju yang dikenakan menggambarkan bentuk dan warna bulu-bulu burung merak. Selendang yang dipenuhi payet menggambarkan ekor merak yang sedang berkembang, mahkota berbentuk kepala merak yang disebut siger. Berbagai warna dan bentuk kostum memiliki unsur estetika yang meliputi warna maupun bentuk. Tarian yang dibawakan oleh penari perempuan yang berjumlah dua penari atau lebih dilakukan secara bersamaan. Musik pengiring tarinya, yaitu musik tradisional gamelan.

Objek penelitian yang dipilih ialah kostum Tari Merak. Mendeskripsikan unsur estetika bentuk visual sehingga akan mencakup beberapa aspek seperti unsur garis, bentuk, warna, tekstur, dan lain sebagainya. Beberapa unsur tersebut akan membantu menghasilkan pendeskripsian secara rinci bentuk visual kostum Tari Merak secara estetik.

Model pendekatan estetik dapat dilakukan atas dua sisi, yaitu pendekatan melalui filsafat seni dan pendekatan melalui kritik seni. Dalam kajian filsafat seni, objek desain dapat diamati sebagai sesuatu yang mengandung makna simbolik, makna sosial, makna budaya, makna keindahan, makna ekonomi, makna penyadaran, ataupun makna religius. Sedangkan dalam kritik seni, objek amatan cenderung diamati sebagai objek yang mengandung dimensi kritis, seperti dinamika gaya, teknik pengungkapan, tema berkarya, ideologi estetik, pengaruh terhadap gaya hubungan dengan perilaku. ${ }^{1}$

Pendekatan dalam suatu penelitian memiliki dua pokok pembahasan yang sebenarnya saling terkait. Memandang karya seni tari secara bentuk fisik atau interestetik dan melalui konteks bagaimana tari tersebut dipandang bersama ilmu pengetahuan yang lain atau ekstraestetik. ${ }^{2}$

Memandang estetika sebagai suatu filsafat, pada hakikatnya telah menampatkan estetika pada suatu titik dikotomis antara realitas dan abstraksi, serta antara keindahan dan makna. Apa yang disimak dalam estetika bukan lagi keindahan dalam pengertian konvensional, melainkan telah bergeser ke arah sebuah wacana dan fenomena. Estetika dalam karya seni modern, didekati melalui pemahaman filsafat seni yang merujuk kepada konsepkonsep keindahan zaman Yunani atau estetika Platonian hingga masa abad pertengahan yang

\footnotetext{
${ }^{1}$ A Sachari. 2005, Pengantar Metodologi Penelitian Budaya Rupa, Bandung: Penerbit Erlangga, p. 119.

${ }^{2}$ Y. Sumandiyo Hadi, (2007), Kajian Tari Teks dan Konteks, Yogyakarta: Pustaka Book Publisher, p. 21.
} 
dikenal estetika Newtonian dan estetika Positivistik. $^{3}$

\section{PEMBAHASAN}

A. Tari Merak Jawa Barat

Tari Merak berasal dari kota Bandung Provinsi Jawa Barat. Seiring perkembangan zaman tari Merak mulai mengglobal. Fenomena ini membuat Tari Merak tidak hanya dijumpai di Jawa Barat, tetapi di daerah lain seperti Jawa Tengah. Tari Merak pertama kali diciptakan oleh R. Tjetje Somantri pada tahun 1955 dan ditampilkan dalam acara Konprensi Asia Afrika bertempat di Gedung Merdeka. Tarian yang dijumpai pada tahun 1965 sampai saat ini adalah Tari Merak ciptaan Irawati Durban Ardjo. Tarian yang telah dibuat ulang sehingga sudah berbeda baik gerakan, kostum, dan penampilannya. ${ }^{4}$

Pemicu munculnya Tari Merak karya Irawati adalah ketika Presiden Soekarno memberi tugas untuk mempersiapkan rombongan kesenian NYWF (New York World's Fair) 1965. Banyak hal yang didapat oleh Irawati ketika melakukan pengamatan burung merak. Gerakan ini bercerita tentang pesona burung merak jantan yang bersolek menarik hati sang merak betina. Selain itu ada

${ }^{3}$ A Sachari. 2005, Pengantar Metodologi Penelitian Budaya Rupa, Bandung: Penerbit Erlangga, p. 121.

${ }^{4}$ Ending Caturwati, 2000, R Tjetje Somantri (1892-1963)

Tokoh Pembaharu Tari Sunda. Tarawang, Giwangan Yogyakarta, p. 134. beberapa gerakan burung merak lainnya yang menyimbolkan Tari Merak.

Tarian yang Irawati buat memiliki nuansa klasik Sunda baru yang disebabkan oleh banyaknya unsur lain yang digunakan. Panduan proses pembuatan Tari Merak Irawati tidak terlepas dari karya Tjetje. Mengingat, kemudian diubah dan ditambah sesuai imajinasi. Irawati lulusan dari ITB (Intitut Teknologi Bandung) Jurusan Interior Seni Rupa, ini adalah salah satu alasan Irawati untuk menginovasikan kostum dan gerak pada tari Merak.

B. Kostum Tari Merak Karya Irawati Durban Ardjo

Tari Merak memiliki beberapa bagian penting yaitu, tata rias (make-up), gerakan, dan kostum. Semua bagian tersebut memberikan efek yang sangat besar pada pertunjukan Tari Merak. Jika salah satu bagian ini terlupakan atau tidak dilakukan secara maksimal maka kesan yang ditampilkan penari tidak tersampaikan dengan sempurna, begitupun yang didapatkan oleh penonton tidak dapat diterima dengan baik.

Proses pembuatan kostum Tari Merak ini Irawati tidak sendiri, ia dibantu oleh beberapa orang terdekatnya yang salah satunya ialah Drs. Barli Sasmitawinata. Barli merupakan penata kostum Viatikara yang bekerjasama dengan Irawati untuk melukiskan 
kostum yang ada dalam konsep pemikiran Irawati. Selain Barli, Irawati juga dibantu oleh Ibu Kusumah yang merupakan kakak iparnya sendiri sejak tahun 1963.

Tidak hanya sebatas pembuatan kostum, penambahan asesoris membuat tari ini semakin sempurna. Asesoris yang dibuat berbahan kulit sapi yang kemudian ditatah, diberi cat berwarna keemasan serta diberi hiasan payet yang terbuat dari manik-manik (mute). Sedangkan pembuatan siger, dipesan langsung oleh Paul Kusardi selaku koreografer Grup Tari Viatikara. Siger tari Merak berbentuk seperti kepala burung merak yang ia gambarkan dengan gerakan tangannya.

\section{Bagian-Bagian Pada Kostum Tari Merak} 1. Siger (Mahkota)

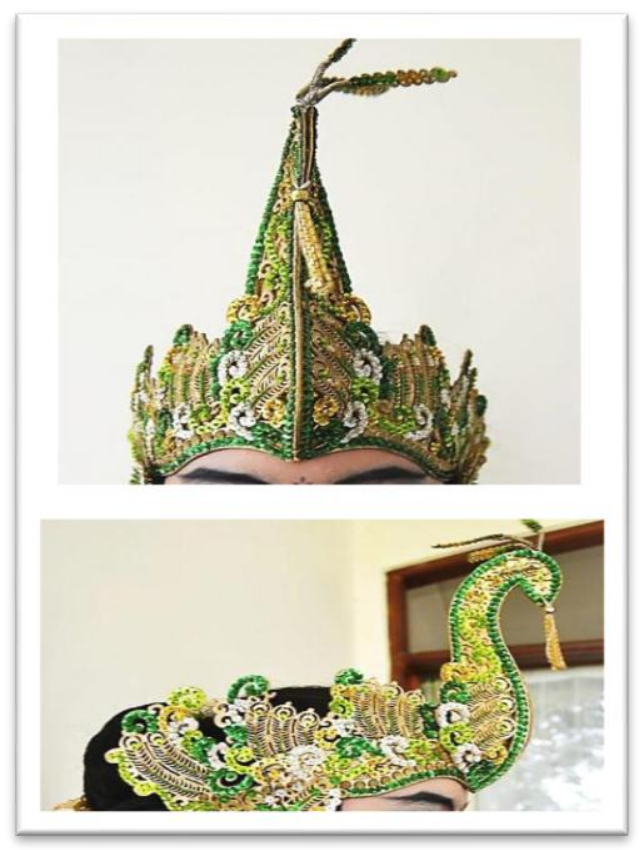

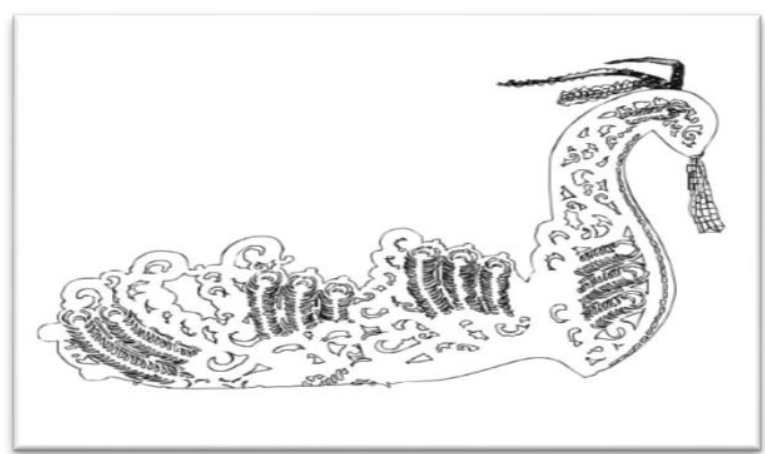

Ilustrasi

Nama : Siger

Garis : Lengkung dekoratif

Bentuk : Kepala burung merak, dekoratif bulu ekor merak

Ornamen : Ulir, Ragam hias binatang

Warna : Hijau tua, hijau muda, kuning, putih

$$
\begin{gathered}
\text { Gambar 1 } \\
\text { Siger (Mahkota) Kostum Tari Merak } \\
\text { Sumber: Dokumentasi pribadi, } 2018
\end{gathered}
$$

Siger atau mahkota yang digunakan pada kepala penari, memiliki bentuk seperti kepala burung merak. Lengkap dengan jambul di atas siger layaknya jambul merak. Memakai mute yang dibuat memanjang pada bawah paruh sigernya, sehingga ketika menari ada bagian yang bergerak pada siger. Bentuk siger tari Merak tidak datar, melainkan meliuk-liuk menyerupai bulu merak sehingga menambah unsur estetika pada bentuk siger. Bahan yang digunakan adalah kulit sapi yang ditatah kemudian diberi cat berwarna keemasan. Siger diberi payet dengan berbagai macam warna seperti hijau, putih, kuning, dan payet berwarna keemasan.

Foto 


\section{JOGED}

ISSN: $1858-3989$

\section{Susumping}

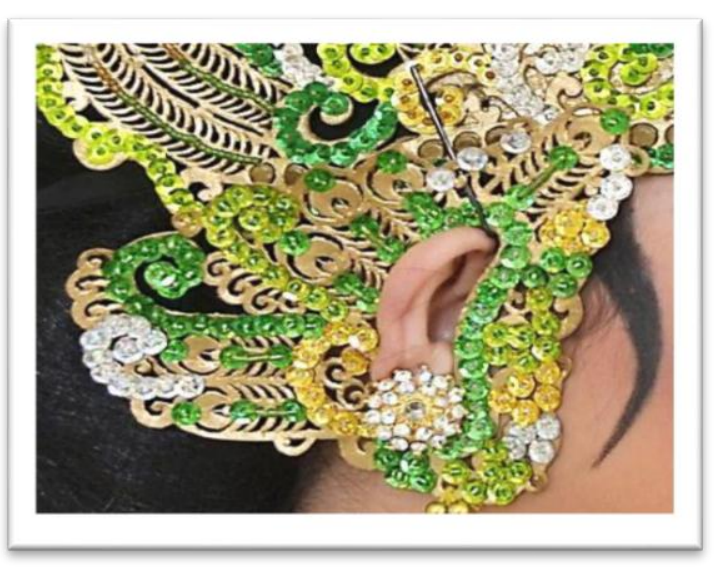

Foto

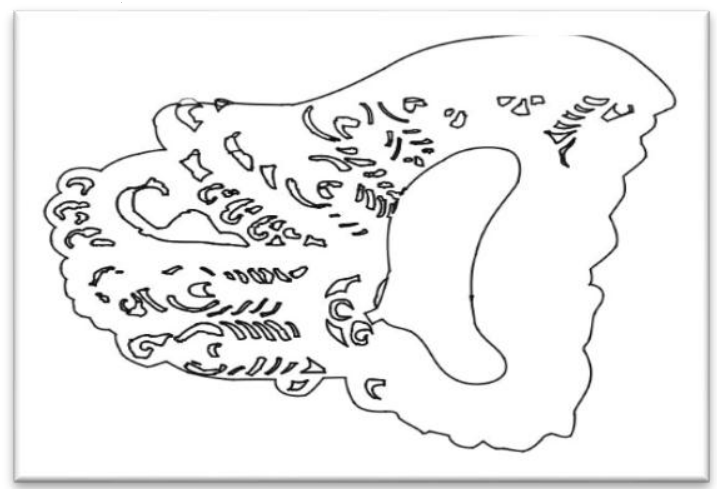

Ilustrasi

\section{Nama : Susumping \\ Garis : : Lengkung dekoratif \\ Bentuk : Telinga, dekoratif bulu ekor \\ merak \\ Ornamen : Ulir, Ragam hias binatang \\ Warna \\ kuning, putih}

dari lengkungan-lengkungan tersebut menciptakan bentuk motif bulu Merak. Bentuk susumping mirip dengan bentuk telinga namun ukurannya lebih besar dari telinga sesungguhnya. Dengan menggunakan bahan kulit sapi, susumping memiliki unsur-unsur bulu merak yang diukir dan kemudian dipercantik dengan cat berwarna keemasan. Pada susumping diberi payet dari berbagai macam warna, yaitu kuning keemasan, hijau muda, hijau tua, dan silver.

\section{Giwang (Anting)}
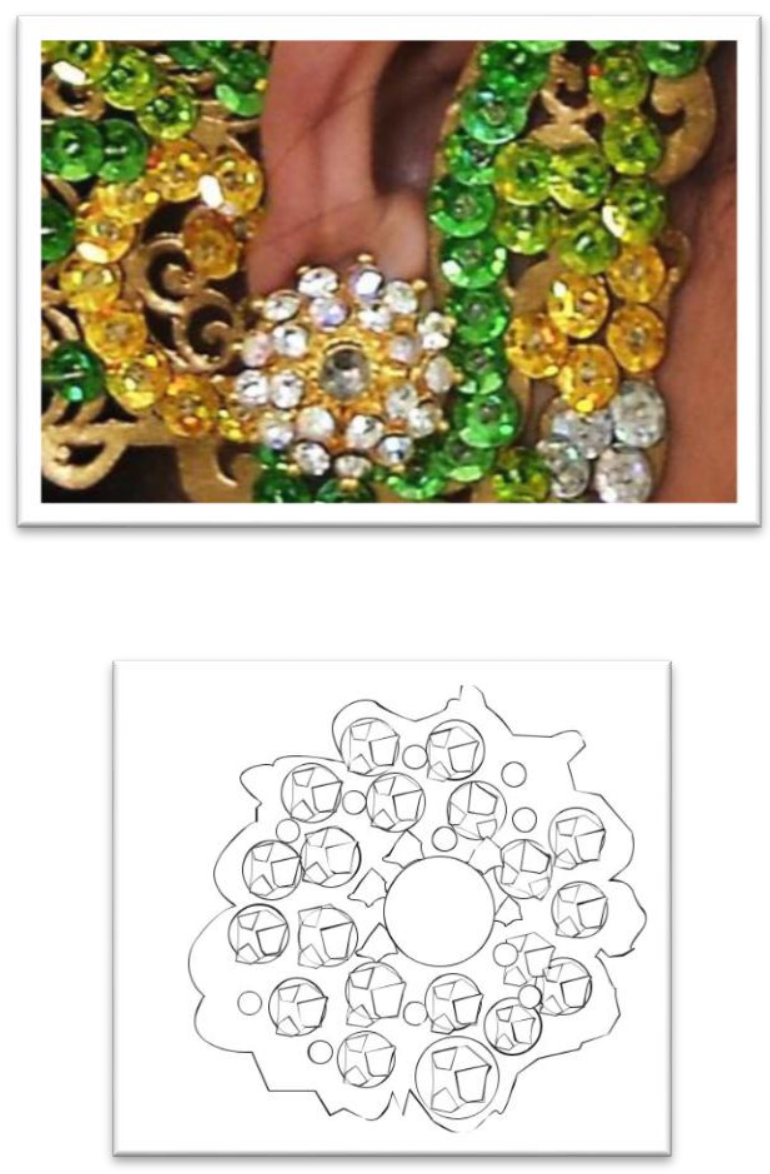

Gambar 3 telinga penari dengan cara disisipkan. Garis yang digunakan pada susumping adalah garisgaris lengkung yang sangat dekoratif sehingga

\section{Gambar 2}

Susumping Kostum Tari Merak Sumber: Dokumentasi pribadi, 2018 Susumping merupakan aksesoris yang penggunaannya satu kelompok dengan siger.

Susumping digunakan pada kedua 


$$
\text { Giwang atau anting merupakan }
$$
perhiasan yang sering digunakan kaum wanita pada telinganya. Penggunaannya dijepitkan pada daun telingan bawah seperti yang digunakan pada telinga penari. Anting yang digunakan memiliki garis-garis lengkung yang kemudian membentuk lingkaran. Bentuk anting memiliki kompsisi perpaduan lingkarang yang menyerupai bunga, berwarna keemasan dan diberi permata.

\section{Kelat bahu}
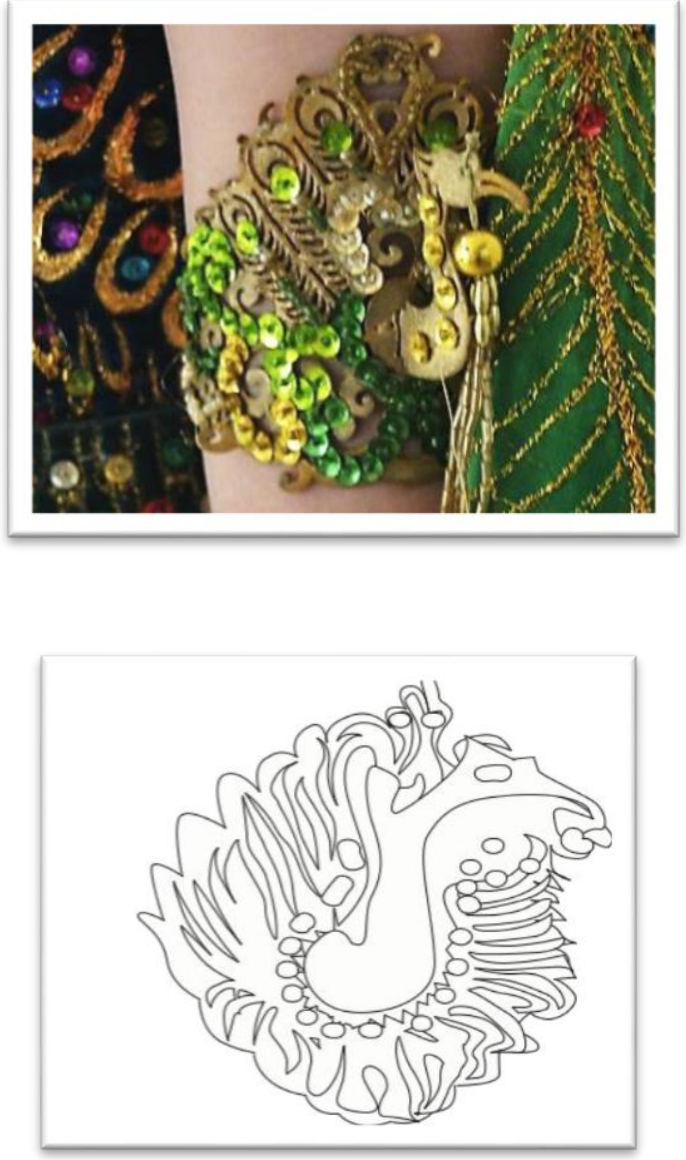

Gambar 4

Kelat Bahu Kostum Tari Merak Sumber: Dokumentasi pribadi, 2018
Kelat bahu memiliki garis lurus pada tali yang berfungsi mengikat pada lengan penari. Sedangkan pada bagian depan kelat bahu memiliki bentuk yang menyerupai burung Merak, bentuk ini terdiri dari garisgaris lengkung dan garis dekoratif. Bentuk burung Merak yang digunakan pada kelat bahu disederhanakan sehingga tidak terlalu rumit. Berbahan dasar kulit sapi yang kemudian dibentuk sesuai yang dibutuhkan. Bagian yang memiliki warna hijau tua, hijau muda, putih, kuning, dan kuning keemasan.

\section{Garuda Mungkur}
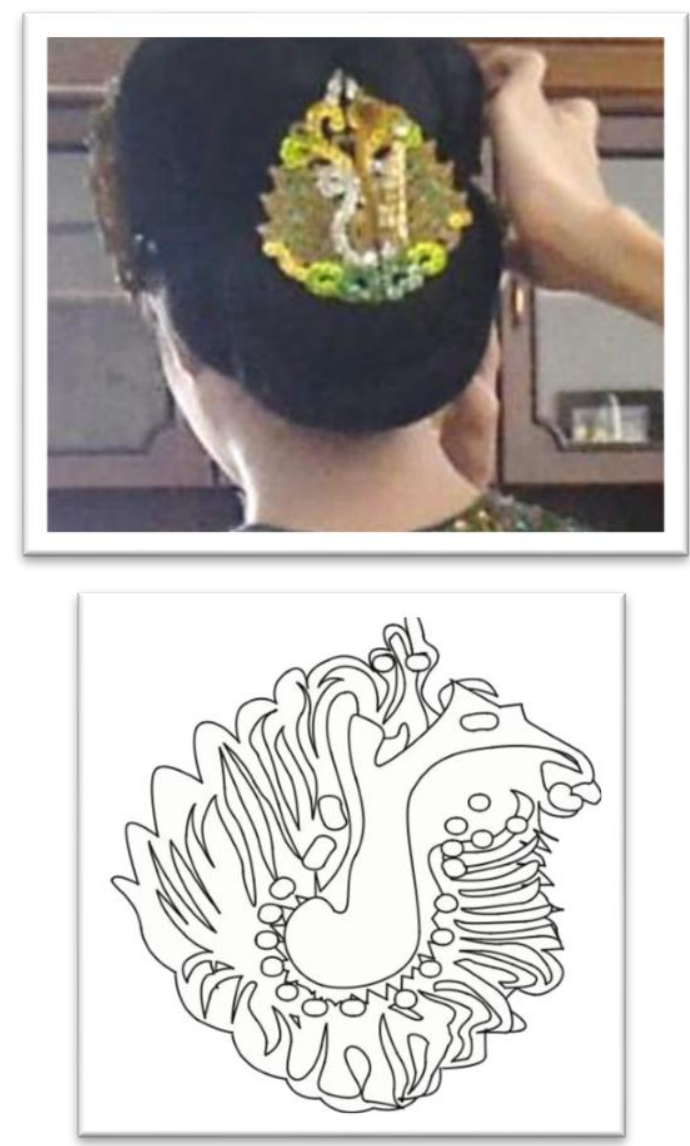

Gambar 5

Garuda Mungkur Kostum Tari Merak Irawati Sumber: Dokumentasi pribadi, 2018 
Garuda mungkur adalah bentuk pengalihan esensi dengan membuat ukiran berbentuk burung Merak dari kepala hingga ekor. Garuda mungkur diletakkan pada bagian belakang sanggul penari.

\section{Gelang tangan}
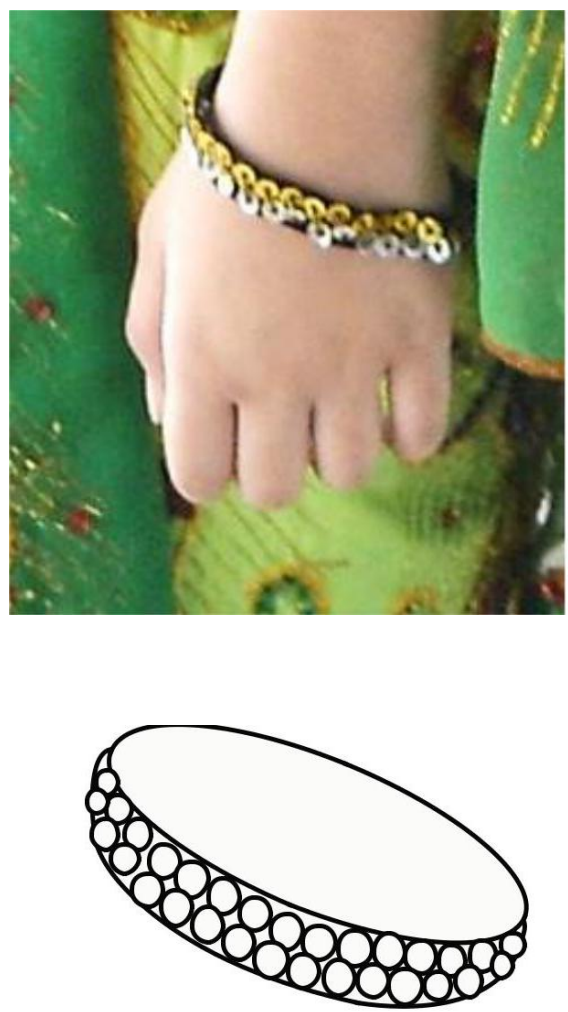

\section{Gambar 6}

Gelang Tangan Kostum Tari Merak Sumber: Dokumentasi pribadi, 2018

Gelang yang berbentuk persegi Panjang, akan berubah bentuk menjadi lingkaran ketika digunakan oleh penari. Ornamen pada gelang dipenuhi dengan hiasan berbentuk lingkaran yang biasa disebut mute. Bahan pembuatan gelang menggunakan bahan dasar kulit sapi. Sedikit perbedaan dapat terlihat pada warna dasar gelang, yaitu warna hitam.

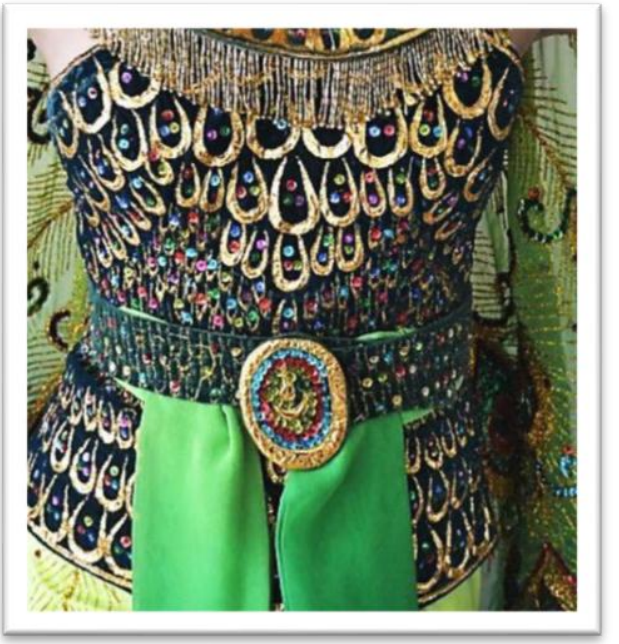

7. Kemben

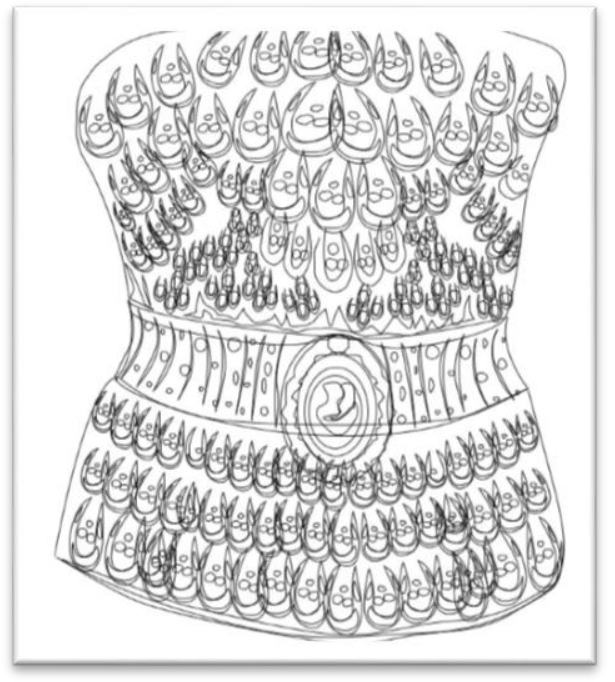

Gambar 7

Kemben Kostum Tari Merak Sumber: Dokumentasi pribadi, 2018

Garis lurus dan lengkung menjadi satu pada bentuk kemben. Bentuk kemben mengikuti bentuk tubuh penari mulai dari atas dada hingga bagian pinggang. Bahan dasar pembuatan kemben adalah kain bludru berwarna hitam, warna hitam sendiri memiliki 
arti kekokohan, tegak, dan kuat. Penggunaan kemben atau bagian tengah tubuh merupakan bagian yang terkokoh dibanding tangan ataupun kaki. Selain warna hitam, kemben memiliki warna keemasan yang terdapat pada bentuk motif bulu Merak yang disusun rapi pada kemben. Penyusunan bulu merak, memiliki bentuk besar pada ujung-ujung kemben dan mengecil pada bagian tengah atau perut. Penyusunan ini bertujuan agar kemben membuat tubuh penari terlihat lebih langsing ketika menari.

\section{Ekor}

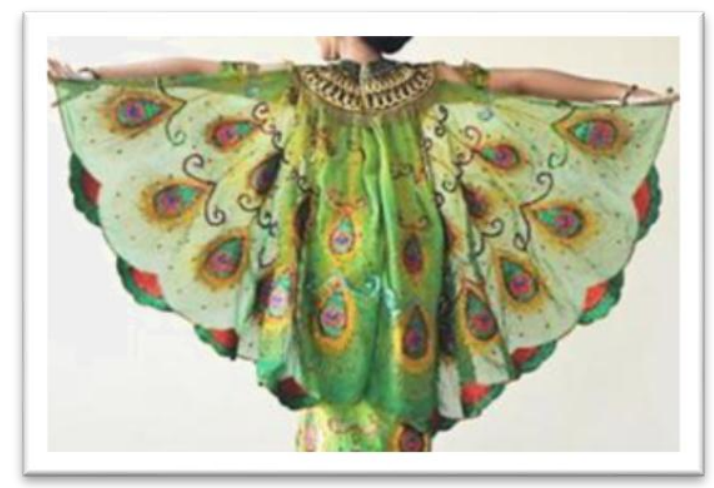

Gambar 8

Ekor Kostum Tari Merak

Sumber: Dokumentasi pribadi, 2018

Bentuk ekor kostum tari Merak pada dasarnya adalah setengah lingkaran yang terdiri dari garis lengkung, garis lurus, dan garis-garis gelombang yang sangat dekoratif. Ekor pada kostum merupakan representasi keindahan ekor Merak yang dimilikinya. Ekor kostum Tari Merak terdiri dari susunan motif ekor Merak. Warna dasar ekornya, yaitu hijau muda yang memiliki arti kemakmuran dan kesejukan, kemudian ditambah aksen bulu ekor Merak yang memiliki warna merah, biru, hijau tua, kuning seperti bulu ekor Merak. Penggunaan ekornya, diletakkan pada belakang punggung penari agar tidak mengganggu gerakan tari. Panjang ekornya sampai mata kaki, agar lebih efektif ketika menari dan tidak terinjak-injak. Pada ujung ekor kostum diberi tali kecil untuk memudahkan penari ketika melebarkan ekornya. Hiasan pada ekor kostum menggunakan benang yang memiliki warnawarna berkilau. Sedangkan penggunaan warna biru, hijau dan merah merupakan warna yang diambil dari burung Merak sendiri.

9. Ikat pinggang
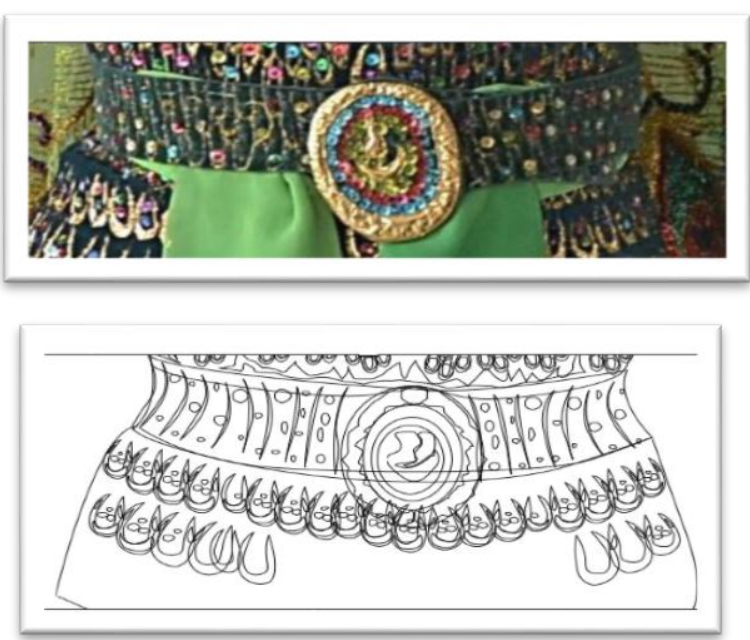
Nama : Ikat pinggang
Garis : Lurus
Bentuk : Persegi Panjang
Ornamen : Lingkaran
Warna : Hijau, kuning, kuning keemasan,
merah, biru, ungu.

\section{Gambar 9}

Ikat Pinggang Kostum Tari Merak Sumber: Dokumentasi pribadi, 2018 
Ikat pinggang digunakan untuk merekatkan antara kemben, sinjang, dan selendang. Bahan dasarnya adalah kain bludru yang berwarna hitam lengkap dengan manikmanik berwarna hijau, kuning, kuning keemasan, merah, biru, ungu yang disusun dengan benang warna kuning emas. Depannya menggunakan hiasan berbentuk lingkaran, hiasan tersebut seperti bros fungsinya sebagai pengunci selendang.

\section{Kacih}
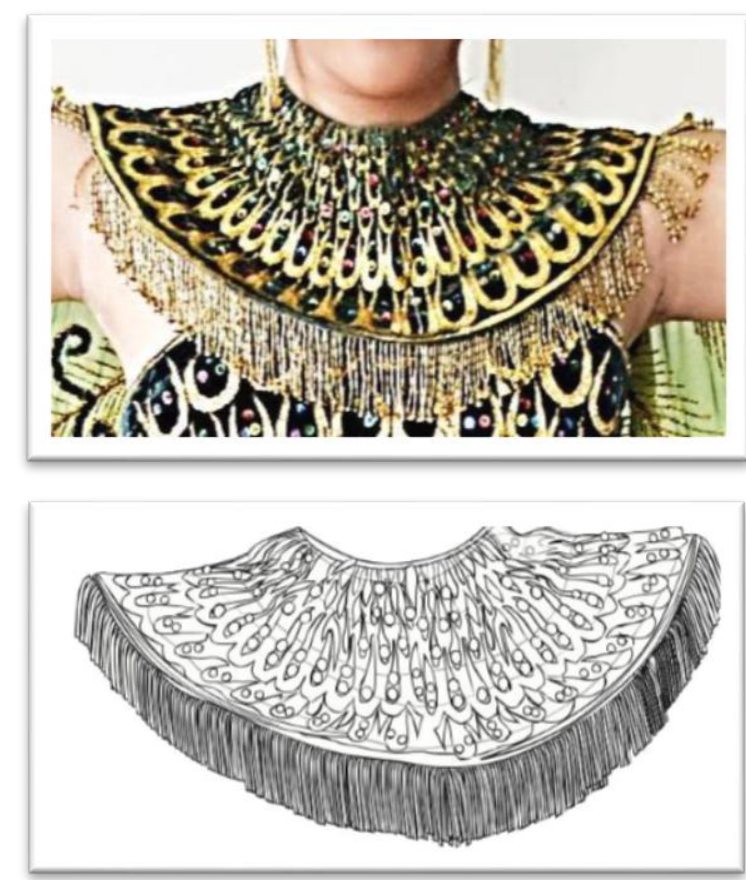

Gambar 10

Kacih Kostum Tari Merak

Sumber: Dokumentasi pribadi, 2018

Kacih atau yang biasa disebut apok merupakan busana kostum yang tujuannya menutupi bagian dada penari. Bentuk kacih terdiri dari garis lengkung yang membentuk lingkaran dan penggunaannya dari depan ke belakang. Bahan dasar kacih sama dengan bahan dasar sabuk dan kemben, yaitu kain bludru. Kacih memiliki warna dasar hitam seperti kemben dan ikat pinggang yang memiliki arti kokoh, tegak, dan kuat.

\section{Selendang dan Sinjang}

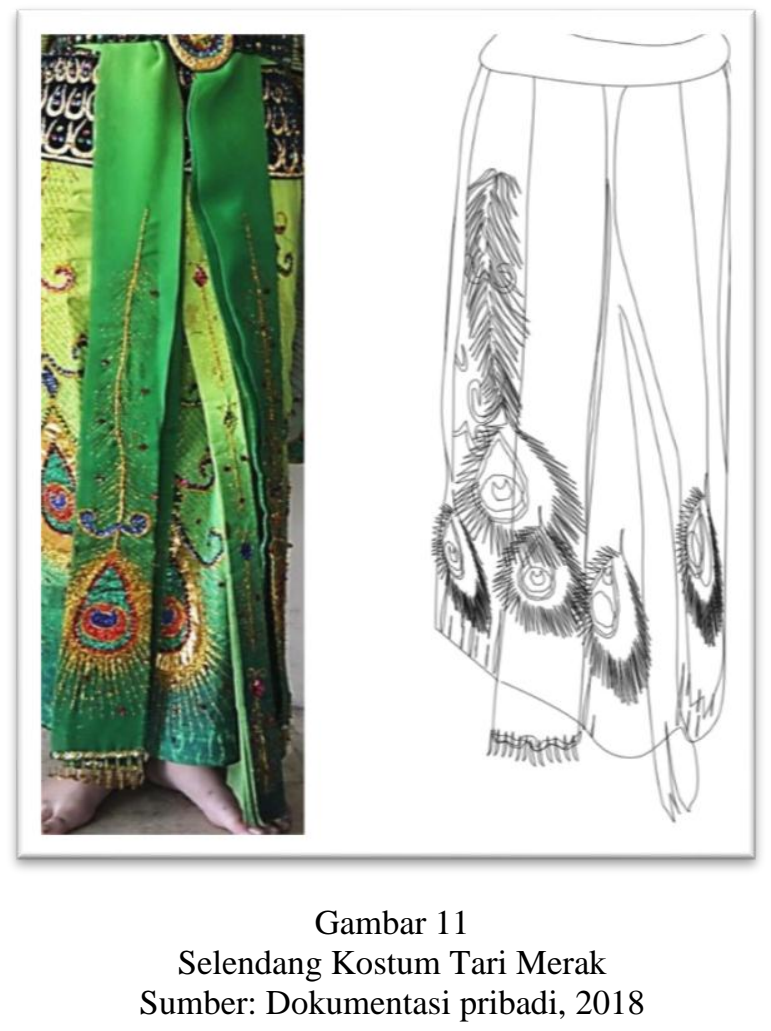

Selendang memiliki garis-garis lurus yang berbentuk persegi panjang. Bentuk dasar selendang seperti sinjang namun berbeda dengan sinjang, selendang dilipat memanjang sehingga memiliki tumpukan-tumpukan kain yang akan melebar ketika ditarik oleh penari. Warna selendang merupakan gradasi dari warna hijau tua pada bagian ujung selendang dan hijau muda pada bagian tengah. Warna hijau memiliki arti kesuburan dan kesejukan 
atau yang berarti kain adalah bagian kostum tari Merak yang berbentuk menyerupai rok. Bentuk sinjang merupakan kumpulan garis lurus yang membentuk persegi panjang. Pada bagian depan sinjang, kain 018bentuk rempel kecil. Bentuk ini sering digunakan pada busana klasik Sunda dan Jawa. Begitupun pada pengantin, fungsinya ialah agar langkah orang yang menggunakannya terjaga atau anggun penuh etika.

Warna yang digunakan pada sinjang ialah warna hijau muda dan hijau tua, selain memiliki arti kesuburan dan kesejukan warna ini mempresentasikan bulu ekor merak yang dominan berwarna hijau. Sinjang menggunakan motif bulu Merak yang disusun rapi memanjang sama seperti yang terdapat pada ekor dan sinjang. Unsur estetis pada bagian ini terlihat pada motif bulu ekor Merak yang menggunakan benang yang berkilau warna kuning keemasan, merah, hijau, biru, dan dibuat secara rapi.

\section{PENUTUP}

Tari Merak merupakan jenis tarian tontonan (pertunjukan). Tarian ini merepresentasikan keindahan yang dimiliki oleh burung Merak. Orang yang pertama menciptakan Tari Merak adalah Rd. Tjetje Somantri pada tahun 1955. Kemudian Tari Merak Irawati Durban Ardjo membuat kembali pada tahun 1965 yang bertujuan untuk dipertunjukkan pada misi kesenian Soekarno. Tari Merak yang sering kita jumpai pada saat ini merupakan Tari Merak karya Irawati.

Kostum Tari Merak diinovasikan oleh Irawati. Irawati mengonsepnya melalui ide-ide kreatif dan memindahkan esensi burung Merak pada bentuk visual. Bagian pada kostum Tari Merak Irawati yaitu, siger (mahkota), susumping, giwang (anting), kelat bahu, garuda mungkur, gelang tangan, kemben, ekor, ikat pinggang, kacih, selendang, dan sinjang. Kostum yang memiliki banyak unsur estetika seperti garis (lurus, lengkung, bergelombang), bentuk (lingkaran, setengah lingkaran, persegi panjang, ekor merak, dan penyederhanaan burung merak), ornamen (ragam hias binatang, ragam hias tumbuhan, geometris, ulir). Beberapa motif yang digunakan yaitu motif ekor, bulu, ataupun keseluruhan bentuk.

\section{DAFTAR SUMBER ACUAN}

Caturwati, Ending. 2000. $R$ Tjetje Somantri (1892-1963) Tokoh Pembaharu Tari Sunda. Tarawang, Giwangan Yogyakarta. Dibia Widaryanto, Suanda. 2006. Tari Komunal. Jakarta: Lebaga Pendidikan Nusantara.

Endo Suanda, Sumaryono. 2006. Tari Tontonan: Buku Pelajaran Kesenian 
Nusantara. Penerbit: Lembaga

Pendidikan Seni Nusantara.

Hadi, Y. Sumandiyo. 2007. Kajian Tari Teks

dan Konteks. Yogyakarta: Pustaka

Book Publisher.

Sachari, A. 2005. Pengantar Metodologi

Penelitian Budaya Rupa. Bandung:

Penerbit Erlangga.

Somaryono, Suanda. 2006. Tari Tontonan.

Jakarta: Lebaga Pendidikan Nusantara.

Subiyantoro, Slamet. 2011. Antropologi Seni

Rupa. Penerbit: Sebelas Maret

University Press.

Sugiyono. 2010. Memahami Penelitian

Kualitatif. Bandung: Alfabeta. 